\title{
Synthesising knowledge for lean product development process of a low noise jet engine
}

\section{Zehra C. Araci}

University of Sharjah,

P.O. Box 27272, Sharjah, UAE

Email: zaraci@sharjah.ac.ae

\section{Ahmed Al-Ashaab}

Cranfield University,

Cranfield, Bedfordshire MK43 0AL, UK

Email: abohabbas@yahoo.co.uk

\section{Muhammad Usman Tariq*}

Abu Dhabi School of Management,

Salam Street 31st, Abu Dhabi, P.O. Box 6844, UAE

Email: m.tariq@adsm.ac.ae

*Corresponding author

\section{Jan H. Braach}

Dubai Airports,

Terminal 1, Dubai International Airport, P.O. Box 2525, Dubai, UAE

Email: jan.braasch@dubaiairports.ae

\begin{abstract}
The product development process is one of the most challenging stages of a product life cycle due to several reasons. Having the right knowledge environment during the design process may eliminate the waste of cost and time. The aim of this paper is to demonstrate a case study where designers can investigate the conflicting parameters about a product and make their decisions based on an accurate knowledge environment that is created by trade-off curves. The product in consideration is a turbofan jet engine with a requirement of noise reduction during takeoff while keeping up with high quality standards.
\end{abstract}

Keywords: knowledge creation and visualisation; knowledge management; lean product development; new product development; trade-off curves; aircraft engine noise reduction; decision making.

Reference to this paper should be made as follows: Araci, Z.C., Al-Ashaab, A., Tariq, M.U. and Braach, J.H. (2021) 'Synthesising knowledge for lean product development process of a low noise jet engine', Int. J. Aerospace System Science and Engineering, Vol. 1, No. 1, pp.3-19. 
Biographical notes: Zehra C. Araci is an Industrial Engineer with more than ten years of academic and industrial experience in quality management systems and lean approaches. She is holding a $\mathrm{PhD}$ degree in Manufacturing, specifically, lean product and process development area. She has consulted for companies in Turkey, guiding them on their journeys to quality certification and excellence awards. She conducted innovative research projects with prestigious firms in the UK and introduced lean hospital initiatives at one of the prestigious hospitals in the Middle East. She has also taught several courses related to innovation, knowledge management and lean thinking.

Ahmed Al-Ashaab is a reader in lean product development, Leader of the LeanPPD Research Group and Course Director of the MSc in Global Product Development and Management at the Manufacturing Department of Cranfield University. He was the Technical Coordinator of the LeanPPD European Project and set-based design expert in the TSB-CONGA project. His research career started after he obtained his $\mathrm{PhD}$ from Loughborough University in 1994. He then worked at ITESM Campus Monterrey in Mexico from 1994 to 2000. He has 26 years of teaching experience in Mexico, Colombia, France and the UK. He has 100 research papers and supervised 150 theses.

Muhammad Usman Tariq has more than 13 years' experience in industry and academia. He has been working as a standards consultant and trainer for industries representing Six Sigma, quality, health and safety, environmental systems, project management, and information security standards. He is one of the few instructors/consultants having Certified Six Sigma Master Black Belt Certification. He has published more than 50 papers in international journals and conferences. He has supervised more than 1,200+ thesis of bachelors, masters, and $\mathrm{PhD}$ students. He is a Certified Higher Education Teacher from Harvard University, USA.

Jan H. Braach is an aviation professional with more than six years' experience in airlines and airports. His career has seen him contribute to high-profile terminal developments, as well as airline and airport operations, strategy definition and strategy implementation. He has worked on a range of initiatives from customer-facing self-service to revenue and cost optimisation programmes, customer privacy and operational efficiency solutions.

\section{Introduction}

Rapid technological changes cause organisations to adopt the fast-paced technological changes for sustainability and continuous improvement of their product development activities. Product designers are facing major challenges due to new technological changes throughout the life cycle of the product. Organisations need a product development approach that can handle the rapid changes along with complex customer requirements to fulfil (Addo-Tenkorang et al., 2016). The complexity of the customer requirements requires increased effort and resources for product development. In the last few decades, lean principles and lean management have offered instruments to overcome the challenge of rapid changes. Lean principles started with the product development field and now expanded to various other fields, i.e., lean healthcare, lean constructions, lean administration, etc. In the field of engineering, promising methods were applied on the production through new methods and approaches. The combination of the lean and 
product development processes addressed the challenges as lean product development (LeanPD); an application of lean principles to product development (Araci et al., 2016). LeanPD requires the right knowledge and environment to create a robust optimal design. LeanPD supports research and development (R\&D) to acquire the required knowledge for improving the quality and design of a product. LeanPD, combined with trade-off curves (ToCs), provides the required environment by acquiring and visualising the knowledge of the product as well as outcomes from the R\&D (Araci et al., 2017; Tariq, 2013). LeanPD is often referred to as the cross functional activity that uncovers the required knowledge and environment for optimal product development. This research aims to address two major areas: creating the right knowledge environment by improving product development processes and providing support to successful decision making for a reduction of aircraft jet engine takeoff noise level (Kopsch, 2016; Gagliardi et al., 2018).

The aircraft manufacturing industry is facing complex product development challenges during production. The challenges include late design changes, rework, communication challenges, lack of knowledge, and expertise (Khan et al., 2013; Tariq, 2013). LeanPD can provide the aircraft manufacturing industry with the right knowledge and environment for successful product development, reducing rework, decreasing cost and minimising project delays caused by inaccurate design solutions (Araci et al., 2017). ToCs combined with LeanPD offer the product designers an effective solution to overcome the challenges and increasing the projects' success rate (Rauch et al., 2016). The Wright Brothers, who succeeded in operating an aircraft for the first time, primarily used ToCs (Kennedy et al., 2014). Aircraft production has improved exponentially since then by gaining popularity with new forms of aircraft. However, there is still scope for numerous improvements, including take off noise as one of the most challenging factors in aircraft manufacturing.

This research aims to demonstrate a case study of an aircraft jet engine where designers may make their decisions based on an accurate and visualised knowledge environment which can be created by trade-off curves. Trade-off curves combine the power of data with the power of the human visual processing system. Additionally, ToCs facilitate the evaluation of multiple conflicting parameters in one graph. ToCs are commonly generated in the form of mathematical algorithms; however, this paper focuses on using real data which has been collected from previous, either successful or failed projects. The data can also be pulled from R\&D or it can be newly generated by modifying existing solutions and reengineering competitors' solutions. Having robust design solutions will enable the product designers to utilise the best solution from previous projects.

The paper proposes a set of possible design solutions in the early stages of the lean product development of an aircraft jet engine. This design set has been developed by turning data into useful knowledge in the form of trade-off curves. Since the data was collected from previous, successful projects, the need for prototyping is eliminated from the initial steps of the product development. Additionally, the developed design-set may support the designers with sufficient knowledge during the set-based concurrent engineering (SBCE) applications until a final optimum solution is achieved. 


\section{Literature review}

\subsection{The role of trade-off curves within lean product development}

The global market is the key driver for organisations to improve their product development process. Advanced product development processes have enabled growth and profit over the last 75 years. The global market increased the international access to products but also exposed organisations to international competition. Innovative design and manufacturing solutions have enabled low barriers of entry and increased pressure for manufacturing high quality products (Biazzo et al., 2016). Product development demands are often changing rapidly, presenting organisations with a need for flexible development and a short time-to-market that requires efficient product development process (Aksoy, 2017). Additionally, there are extremely short periods in the consumer market with huge revenue potentials (Kammerl et al., 2017). Organisations must sustain their market share through continuous product development improvement by balancing time, cost, and quality. The product development must be distinctive for gaining a competitive advantage in the market. Efficient product development provides the opportunity to the manufacturing organisations to use the prior knowledge for continuous improvement of the production processes (Wang and Wang, 2012; Nonaka et al., 2014).

As shown in Figure 1, new products are often the result of a company having identified an unsatisfied customer demand. Traditionally, the development of these new products has been hindered by inefficiencies in the PD process. Among these are lack of knowledge or sufficient research, last-minute changes to the design and associated rework, ineffective process planning and scheduling, internal communication challenges and lack of organisational accountability and process ownership (Khan et al., 2013). Each of these has the potential to significantly increase the time-to-market for any new product. In order to address each of these factors, the lean product and process development (LeanPPD) model has increasingly found application in the manufacturing industries. However, a successful implementation of the LeanPPD model necessitates the presence of a number of enablers, namely value-focused planning and development, the set-based concurrent engineering (SBCE) process, top-down technical leadership, a culture of continuous improvement and a knowledge-based environment (Khan et al., 2013). Among these, SBCE in particular is recognised as a primary driver of efficiency in PD (Al-Ashaab et al., 2013). SBCE arrives at the optimum product/solution through an iterative process comprising of the creation of a design-set, as well as the communication, the trade-off and the narrowing down of the set of potential design solutions (Sobek et al., 1999). This approach, however, heavily relies on access to organisational knowledge, which provides the context for the SBCE process to meet organisational objectives. It is thus imperative that organisations create a knowledge-environment if they aim to improve the efficiency of their PD process. Using an appropriate knowledge-environment in SBCE, companies can reuse and share organisational and process knowledge, and enhance the quality of decisions made during the PD process (Lindlöf et al., 2013; Kennedy et al., 2014; Maksimovic et al., 2014). 
Figure 1 Scope of the paper (why trade-off curves?) (see online version for colours)

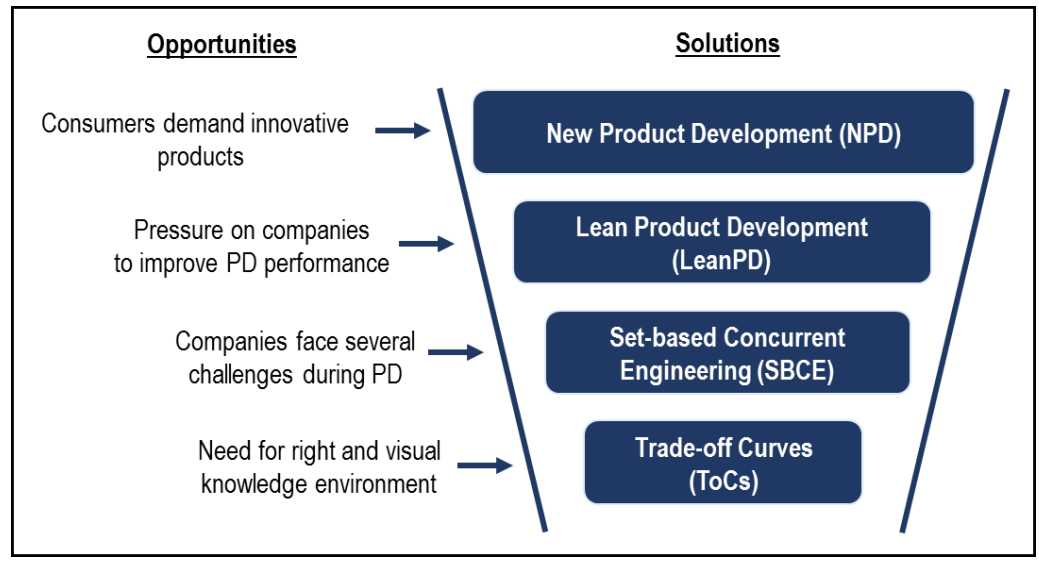

While companies are consequently endeavouring to maximise the use of their organisational knowledge, it is almost never easily accessible, or even quantifiable. One of the models that define and explain the creation of knowledge in organisations is the SECI model proposed by Nonaka et al. (2000), which refers to the socialisation, externalisation, combination and internalisation of knowledge. With regards to organisational knowledge, the key mode of the SECI model is externalisation, the process of converting tacit knowledge (i.e., experience or individual knowledge) into explicit knowledge such as documents, reports and drawings (Nonaka et al., 2000). In this context, Tyagi et al. (2015) have proposed trade-off curves (TOC) as a vital tool for the externalisation mode of the SECI model, as they provide a knowledge-based environment by illustrating and documenting internal knowledge, and thereby making it accessible for use in the PD process (Raudberget, 2010; Correia et al., 2014).

The ability of TOCs to create and visualise knowledge in a simple manner is a key enabler of SBCE applications (Morgan and Liker, 2006; Kennedy et al., 2014). They enable engineers and product designers to compare, in the early stages of design - and therefore ahead of any significant investments of time or monetary resources -, several alternative solutions despite any conflicting attributes that these solutions might have (Ward and Sobek, 2014). TOCs visualise knowledge from previous projects, and allow the company to reuse it without the danger of previously gained knowledge having to be 'reinvented' (Ward and Sobek, 2014). A third key capability of TOCs is their visualisation of underlying physical features and fundamental principles of the product under development, which is essential to making a rigorous and correct decision during the SBCE process (Araci et al., 2016).

It is an inherent property of product development processes that the objectives of stakeholders participating in them differ, as do the properties, the shapes, materials and functionalities being considered for the product (Tariq, 2015). In an environment of conflicting objectives, factors, parameters and elements, accurate decision making is crucial. Impacts of favouring one property over another need to be understood and traded off against one another with a view to maximising positive effects on the objective. TOCs are tools to visualise these relationships and support the decision making (Otto and Antonsson, 1991; Bitran and Morabito, 1999). 
TOCs are defined as follows: a trade-off curve establishes a relationship between two or more design parameters, which is more useful than trade-off data (Sobek et al., 1999).

ToCs can be generated in two-dimensional, three-dimensional or multi-dimensional form, depending on the analytic/analysis need or different types of products. If the design team would like to see relationships between more than two design parameters, in order to make a more accurate decision, these relationships can be visually projected on a three-dimensional trade-off curve (Otto and Antonsson, 1991; Raudberget, 2010) or multi-dimensional trade-off curve (Haselbach and Parker, 2012).

Trade-off curves have been widely referred to in the literature, especially from the 1960s onwards (Pershing, 1968), within a range of disciplines from finance and environmental science to engineering and computer science. In line with real-life manufacturing situations, the most prominent use of trade-off curves is to visualise multi-objective (or multi-criteria) problems with conflicting objective functions. Data for such trade-off curves, however, is often readily available or generated (by algorithms and mathematical calculations) and does not serve the purpose of externalising organisational knowledge.

On the other hand, the number of publications that mention trade-off curves within the PD context is very limited. Kennedy et al. (2014) reported that the earliest use of trade-off curves in PD was by the Wright Brothers in the late 1800s. Unlike many of their rivals, they succeeded in the first manned and heavier-than-air flight, despite their lower budget and even in a shorter time. It is believed that a part of this success was attributable to the use of trade-off curves in the early stages of their PD.

Toyota has used trade-off curves to facilitate their SBCE application (Sobek et al., 1999). 'Jidoka' is used by Toyota as visual management technique that integrates product development process with the lean manufacturing (Morgan and Liker, 2006). It is now easy to visually display the knowledge in a graph for the subsystems that enables the production engineers to explore the design space (Ward and Sobek, 2014) and evaluate design alternatives (Kerga et al., 2014). LeanPD with ToCs provided the opportunity to invent new design solutions during prototype phase, which enabled design engineers to save time and develop new innovative solutions (Womack, 2006; Tariq, 2013). Previous research exhaustively demonstrated how trade-off curves can be generated and utilised throughout the stages of set-based concurrent engineering (Araci et al., 2017; Cooper, 2016).

Knowledge-based trade-off curves play a vital role in lean product development from communication to decision support (Correia et al., 2014). Araci et al. (2016) exhaustively investigated the role of trade-off curves and provided a comparison between math-based and knowledge-based ToCs. While the data for math-based ToCs are generated through mathematical modelling, data for knowledge-based ToCs are obtained from previously experienced projects. Math-based ToCs are not the scope of this paper. Al-Ashaab et al. (2014) briefly indicated the role of ToCs in set-based design process of a single spool turboshaft engine; to identify existing design solutions from previous projects and to save time by visualising the knowledge (Saadon and Talib, 2016). However, the literature still lacks applications of trade-off curves within lean product development of an aircraft jet engine (Tariq et al., 2020). This paper will contribute to the literature by providing such an application. 


\subsection{Aircraft noise challenge}

Aircraft manufacturers are facing complex design issues due to take off noise. Loud aircraft noise impact humans, causing hearing problems which can lead to distraction and reduction in quality of communication (Hebly and Visser, 2015; Schuh et al., 2017). It also increases stress for the people who are living in the close surrounding of airports due to especially loud take-off and landing noise (Gjestland and Granøien, 2016; Sobek et al., 1999). Aircraft manufacturers have been working for years to find the best trade off curve to lower the aircraft noise (Iglesias-Merchan et al., 2015; Kopsch, 2016). Commercialisation and growth of aircraft manufacturing have been under scrutiny due to noise being a serious issue (Lawton and Fujiwara, 2016). Many airports have reached their maximum environmental capacity before development of any further runway and transportation infrastructure (Lefèvre et al., 2017; Sandderg et al., 2017). Thus, one of the most important and complex challenges faced by the advisory council of aeronautics is to reduce the current noise of aircraft by $50 \%(-10 \mathrm{~dB}$ /operation). Several different solutions have been designed and tested to control the noise issue at airports, but it remains high at takeoff and landing time (Chandiramani, 1974; Nogueira et al., 2018).

Airports are trying technological solutions and several measures to reduce the noise like restrictions on use of land, approved procedures to take-off and landing, compensation to residents and operations restrictions, but it has failed to reduce the noise levels due to the increase in air traffic (Papamoschou, 2018; Tortorella et al., 2016). Aircraft manufacturers see more demand for aircraft which comply with the noise regulations and policies set by the airports. In the near future, airports will have to deal with the increased traffic and few traffic slots along with oil shortage which will create even greater problems given current noise abatement measures. Environmental issues can only be solved by moving towards more sustainable air transport, which involves new engine designs and fuselages, the development of new procedures and the implementation of more air traffic paths.

Commercial aircraft segments are focusing to manage the airframe-engine combination along with other components such as flaps, under-carriage with different noise attributes to enhance the air transport (Zaman et al., 2012; Trojanek et al., 2017). Currently, there is a lack of a clear link between the certified noise levels as per aircraft manufacturers and the required noise level regulations. The frequency of the noise emitted from different components of the aircraft still need to be measured in real time as it cannot be measured in static positions. The International Civil Aviation Organisation (ICAO) is also working on a new set of regulations and is implementing strict rules to reduce the noise levels. Other than setting the regulations, the aircraft noise level's impact on the social environment still need to be calculated in monetary terms. Different social cost factors depend on the size of the airport, number of terminals/hubs, flights per day, and level of noise contours (Naqavi et al., 2016).

The social and environmental costs of aircraft include both the take-off and landing noise levels. Such costs vary by the emission depending on the aircraft category, engine type, and damage done by the engine pollution on the human health, materials, and climate. Over the past few years the results indicate a link between the environmental cost and traffic volume on an airport. Organisations are working on predicting the noise levels emitted from engines by using the upwinding method, which uses a finite volume method based on the splitting algorithm of Roe and monotone up-centred schemes for conservation laws (MUSCL) to flow over a grid structure (Nogueira et al., 2018). 


\section{An application of trade-off curves in reducing jet engine noise}

\subsection{Work principles of a turbofan jet engine}

Prior research provides the basis that there are several different parameters that serve a reduction of takeoff and landing noise (Kyprianidis and Dahlquist, 2017). Further, aircraft noise reduction requires technical knowledge along with physics to design the best solution and identification of relevant parameters (Berton et al., 2018; Antoni et al., 2017). The key component of a modern aircraft is the jet engine that enables jet propulsion to reach the required speed. The turbofan engine is the common form of a jet engine as illustrated in Figure 2. A forward force is generated by accelerating the entering gas (air) between the entrance and the exit of the engine. By definition, all air entering the engine must also leave it.

Figure 2 A turbofan jet engine illustrating the airflow to generate thrust (see online version for colours)

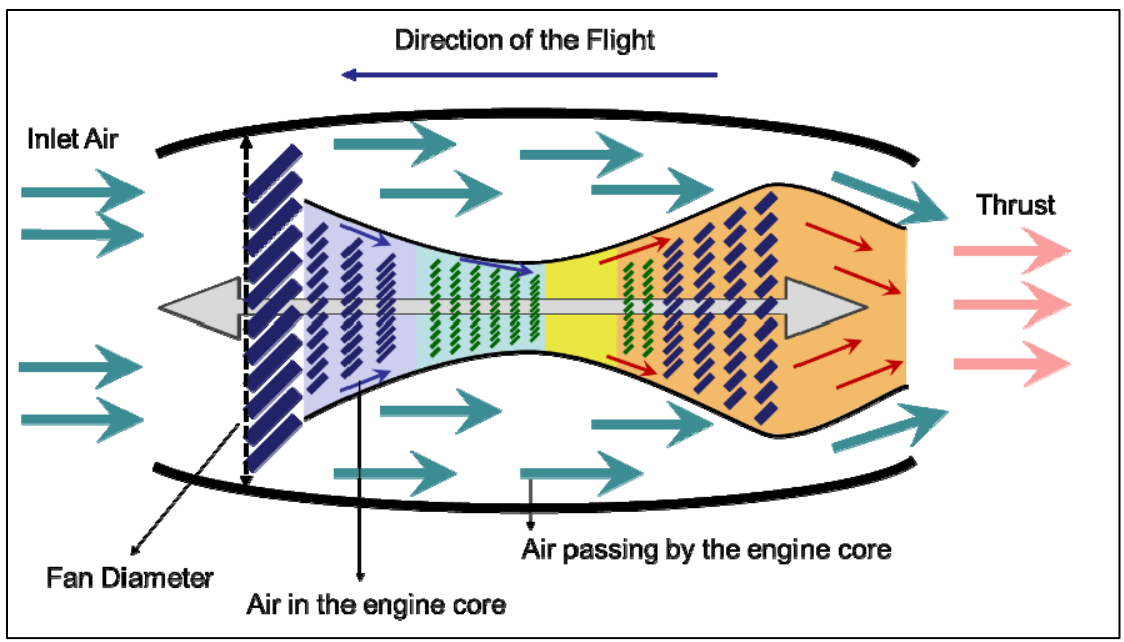

General thrust equation:

$$
\text { FThrust }=\dot{m} e(V e-V 0)-\dot{m} 0(V e-V 0)
$$

The essence of the general thrust equation is that additional thrust can be generated in two ways (NASA, 2020):

1 increasing in the mass flow rate

2 increasing the speed differential of the gas $(V e-V 0)$.

The acceleration of the gas within the engine requires, at present technology levels, that combustion take place. This, in turn, necessitates the transport and consumption of fuel (Balli, 2017). In order to reduce fuel burn but maintain thrust, designers have devised engines in which only a small amount of gas passes through the engine core and is accelerated. A much larger amount of gas bypasses the engine core and is combined with the exhaust gas behind the engine. One way of increasing the mass flow rate is to 
increase the bypass ratio. Bypass ratio is the ratio of the air that passes by the engine core to the air that goes through the engine core and is heated through combustion. For example, if ten portions of air are passing by the engine and only one portion is going through the engine core, the bypass ratio is 10:1. The bypass ratio is always desired to be high, which results in high thrust. Behind the engine, a small amount of high-velocity gas (from the engine core) combines with a large amount of low-velocity gas (from the bypass). The combination of the gases results in a velocity transfer from the high-velocity gas to the low-velocity gas. The combined velocity, however, is larger than the common velocity at the entrance of the engine. Thus, turbofan engines use a small amount of fuel to affect a moderate velocity change of a large amount of gas, thereby creating thrust reasonably efficiently.

\subsection{Variables that affect the takeoff noise of a turbofan jet engine}

Based on the knowledge gained through the literature review and technical analysis of the products as mentioned in the previous sections, the authors found the following important factors that play a significant role in decision making:

1 reliability: the product should perform its required functionality with minimum downtime

2 low noise: the new product should have a lower noise level than the existing products

3 cost: efficient fuel consumption in comparison with the existing turbofan jet engine solutions

4 durability: new product design should be durable according to international standards and must be able to fly with 150 passengers.

The authors also identified the parameters related to the requirements for visualisation using trade-off curves as follows: take-off noise, maximum takeoff mass (MOTM), bypass ratio, thrust and fan diameter. Table 1 displays the parameters and their conflicting relationships based on experts' opinions.

\subsection{Trade-off curves for the take-off noise and identified design parameters}

This section demonstrates 55 different types of jet engines in the form of trade-off curves. Data was collected from publicly available data sources which were released to market as successful commercial products and for which data is available for public use. Minitab software was used for generating the trade-off curves and analysis of the parameters. Data analysis has been performed in order to see the correlations between the conflicting parameters as indicated in Table 1. 
Table 1 Conflicting relationships between the design parameters of a low noise jet engine

\begin{tabular}{lll}
\hline No. & Parameters and relationships & \multicolumn{1}{c}{ Conflicts between the design parameters } \\
\hline 1 & Take-off noise level vs. thrust & $\begin{array}{l}\text { While an aircraft takes off with full power, thrust and } \\
\text { fuel consumption are at a maximum. It was believed } \\
\text { that the noise level is related to the amount of thrust } \\
\text { generated. Therefore, most of the aircraft take-off noise } \\
\text { is caused by the engine. }\end{array}$ \\
& $\begin{array}{l}\text { In order to increase thrust but reduce the take-off noise, } \\
\text { the bypass ratio of the engine can be increased. A } \\
\text { higher bypass ratio produces higher thrust at lower } \\
\text { noise levels. }\end{array}$ \\
& $\begin{array}{l}\text { Take-off noise level vs. } \\
\text { bypass ratio }\end{array}$ \\
$\begin{array}{l}\text { Take-off noise level vs. } \\
\text { maximum takeoff mass } \\
\text { (MTOM) }\end{array}$ & $\begin{array}{l}\text { heavier aircrafts. Through increasing the bypass ratio } \\
\text { by increasing the fan diameter, the engine weight will } \\
\text { also increase which will increase the MTOM. }\end{array}$ \\
Fan diameter vs. bypass ratio & $\begin{array}{l}\text { In order to increase the bypass ratio, the fan diameter } \\
\text { should be increased so that the air intake increases. } \\
\text { vs. MTOM }\end{array}$ \\
& $\begin{array}{l}\text { However, a larger fan results in the engine being } \\
\text { heavier and this leads a higher bypass ratio with a } \\
\text { higher thrust but heavier aircraft. Consequently, } \\
\text { possibility of reducing aircraft engine noise becomes } \\
\text { challenging. }\end{array}$ \\
\hline
\end{tabular}

\subsubsection{Take-off noise vs. thrust}

EPNdB is the metric for take-off noise level which means effective perceived noise in decibel and the metric for thrust is defined as newton $(\mathrm{N})$. Figure 3 displays a positive correlation between the thrust and take-off noise which means that higher thrust causes higher takeoff noise. However, there is one design solution found with a high thrust $(284,500 \mathrm{~N})$ but relatively low noise $(90.1 \mathrm{EPNdb})$ compared to other design solutions.

Figure 3 Correlations between take-off noise and thrust (see online version for colours)

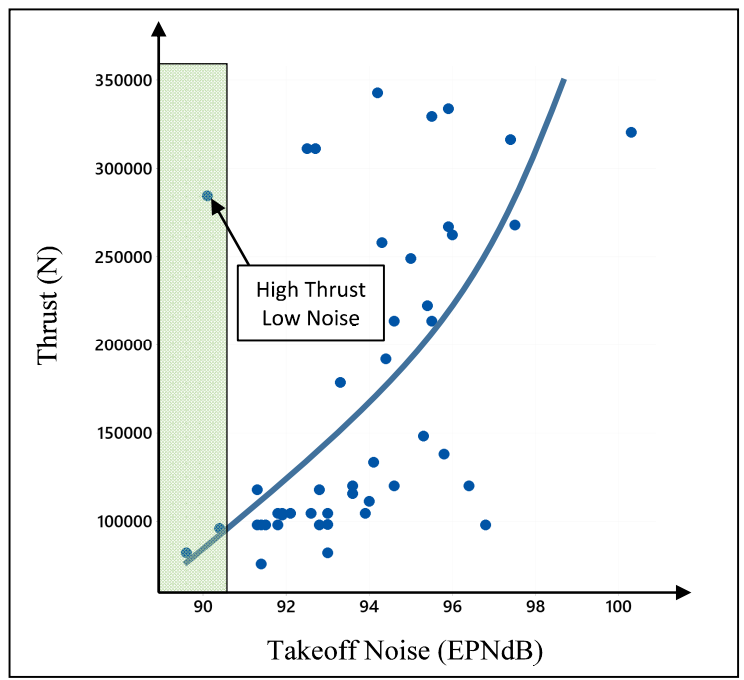




\subsubsection{Take-off noise vs. bypass ratio}

A high bypass ratio is the desirable factor as it is believed that a high bypass ratio results in lower engine noise. However, Figure 4 shows that bypass ratio and take-off noise are not directly dependent, yet there is an indirect correlation. It can be interpreted that there are other factors in addition to the bypass ratio which eventually has an impact on take-off noise level (Araci et al., 2020). Therefore, correlations of bypass ratio, fan diameter and MTOM are investigated and displayed in Figures 6, 7 and 8.

Figure 4 Correlations between take-off noise and bypass ratio (designs on the right hand-side have direct relationship)

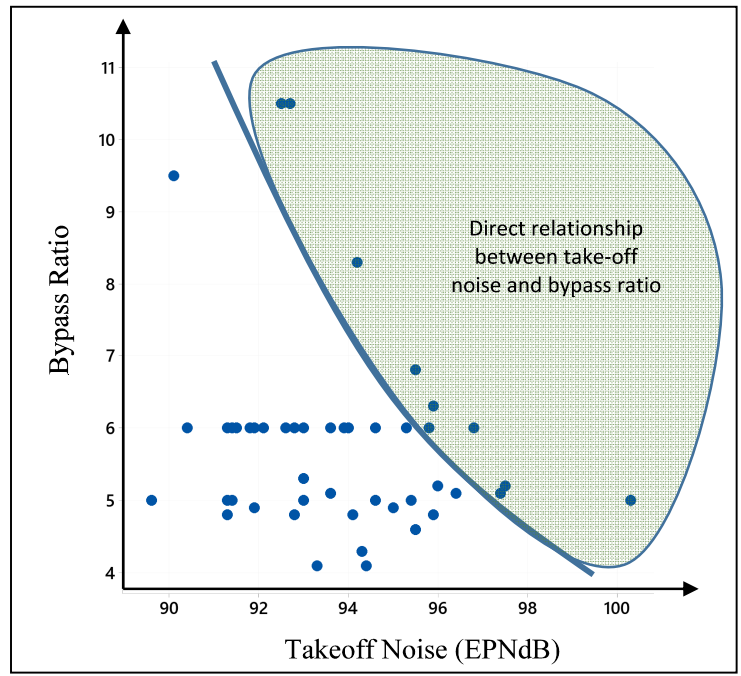

Figure 5 Correlations between take-off noise, thrust and bypass ratio (see online version for colours)

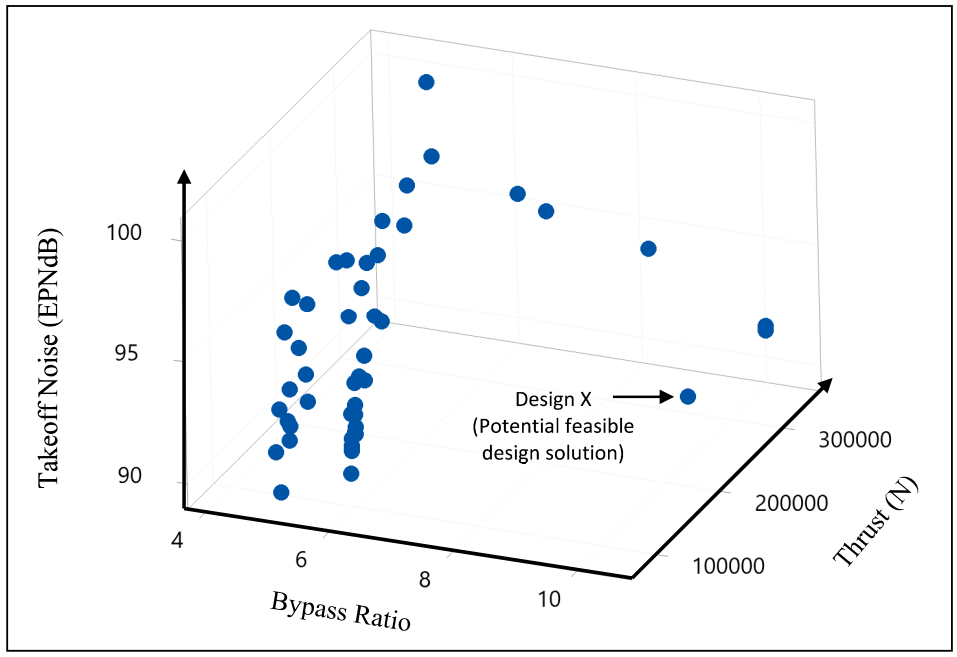


In order to see the relationships among three parameters, the authors generated three-dimensional trade-off curves. As displayed in Figure 5, it was found that one engine (design $\mathrm{X}$ ) has relatively low take-off noise, but a high bypass ratio and high thrust which should be considered within the design set in the early stage of product development. The following section provides further discussions about design X.

Figure 6 Correlations between thrust and MTOM (see online version for colours)

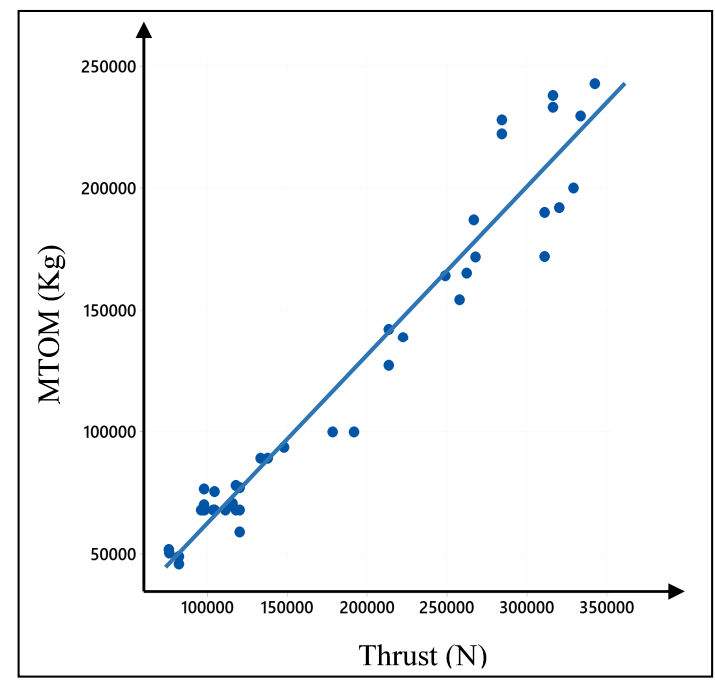

Figure 7 Correlations between take-off noise, thrust and MTOM (see online version for colours)

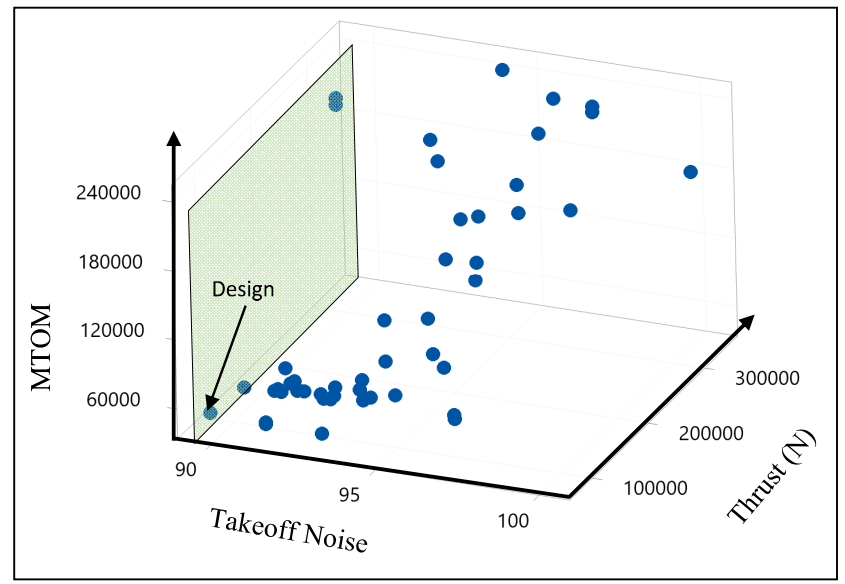

\subsubsection{Take-off noise vs. MTOM}

Some more investigations were carried out to understand the relationships between take-off noise, thrust and maximum take-off mass (MTOM). MTOM is the weight of the aircraft in $\mathrm{kg}$ with an assumption that it operates full capacity (passengers and fuel). A positive strong relation was found between thrust and maximum take-off mass which 
means heavier aircraft require more thrust (see Figure 6). The effect of MTOM on take-off noise has been investigated and displayed in Figure 7 as a three dimensional trade-off curve. It appears that MTOM does not have a significant impact on the noise, however, may facilitate noise reduction indirectly. Findings are discussed in detail in the following section.

\section{Fan diameter vs. bypass ratio vs. MTOM}

There is a positive relation between three parameters: fan diameter, bypass ratio and MTOM as displayed in Figure 8. This positive correlation indicates that a higher bypass ratio requires a bigger fan diameter for more air inlet and higher thrust. However, this increase causes the aircraft being heavier.

Figure 8 Correlations between fan diameter, bypass ratio and MTOM (see online version for colours)

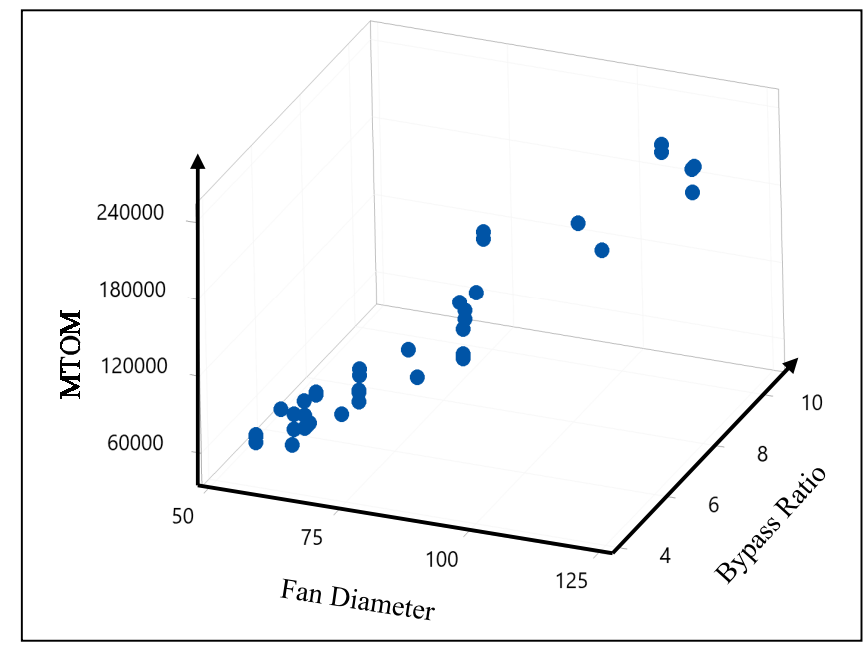

\subsection{Develop a set of potential design solutions that might support product development process of a jet engine}

All trade-off curves were analysed in order to develop a design set of two possible design solutions: design $\mathrm{X}$ and design $\mathrm{Y}$. These designs were further investigated to identify whether they can be reused during the SBCE application of the jet engine. There are several ways of reusing an existing design. For example, designers may reuse an existing solution after minor or major modifications. If these options are not possible, the existing solution may inspire the designers in creating a completely new design.

Design $\mathrm{X}$ has been selected from the generated knowledge-based ToCs since it showed a relatively low take-off noise level compared to other design solutions. However, the MTOM of design X is very high. Consequently, design X requires a higher thrust in order to operate the aircraft. Although design $\mathrm{X}$ has high values of thrust and MTOM, take-off noise is lower than its peers. It was found that ultra-efficient, swept fan blades enable a quieter operation ( $3 \mathrm{~dB}$ quieter than the previous generation engine). Therefore, it can be interpreted that design $\mathrm{X}$ could be an inspiring idea for a new design 
solution which will operate an aircraft with lower MTOM and thrust, considering that thrust is the main cause of the take-off noise.

The authors also selected design $\mathrm{Y}$, as shown in Figure 7. A lightweight, hollow titanium wide chord fan is used in Design $Y$ which reduced the engine weight with low take-off noise level. The authors pointed out an important fact during their analysis. Design Y engines are used in Airbus A340 aircraft which is operated by four engines. Four engines cause more take-off noise than two engines and more noise is emitted by a heavier aircraft. Additionally, the passenger capacity of the aircraft is more than 300 passengers, which is much higher than the required value (150 passengers). Therefore, Design Y engine can be simulated for 150 passengers and the fan system of Design $\mathrm{Y}$ can be reused for the new design in order to reduce the engine weight and the take-off noise level.

Both existing designs, design $\mathrm{X}$ and design $\mathrm{Y}$, are proposed to be considered as reusable knowledge for future designs through the application of SBCE, which is not the scope of this paper. Converging the characteristics of these two solutions may lead to the development of a feasible solution which meets all the customer requirements.

\section{Conclusions}

In the last few decades, lean principles and lean management have offered instruments to overcome the challenges of rapid changes to make projects successful. The knowledge gained from both successful and failed projects is a significant source for future improvements. Designers and production engineers can use trade-off curves for creating the right knowledge environment to enhance their designs. This research presented the importance of trade-off curves and lean product development in overcoming the aircraft noise challenges using the previously attained knowledge and creating the right knowledge environment in the early stages of the product development process. Moreover, this paper proposed a design-set out of 55 successful previous projects without the need of prototyping and intense resource investment. Two feasible design solutions $\mathrm{X}$ and $\mathrm{Y}$ were tested hypothetically to be reused, after modifications to develop the best design set for a low noise turbofan jet engine. The case showed that thrust, fan diameter, engine weight, MTOM and bypass ratio are important parameters to be considered during the development of a low noise turbofan jet engine. Aircraft manufacturers can use the findings of this research to develop a better design using the available trade-off parameters knowledge.

\section{References}

Addo-Tenkorang, R., Helo, P. and Kantola, J. (2016) 'Engineer-to-order product development: a communication network analysis for supply-chain's sustainable competitive advantage', Supply Chain Strategies and the Engineer-to-Order Approach, pp.43-59, IGI Global.

Aksoy, H. (2017) 'How do innovation culture, marketing innovation and product innovation affect the market performance of small and medium-sized enterprises (SMEs)', Technology in Society, Vol. 51, No. 1, pp.133-141. 
Al-Ashaab, A., Golob, M., Attia, U.M., Khan, M., Parsons, J., Andino, A., Perez, A., Guzman, P., Onecha, A. and Kesavamoorthy, S. (2013) 'The transformation of product development process into lean environment using set-based concurrent engineering: a case study from an aerospace industry', Concurrent Engineering Research and Applications, Vol. 21, No. 4, pp.268-285.

Al-Ashaab, A., Golob, M., Oyekan, J., Araci, Z.C., Khan, M., Deli, D. and Al-Ali, E. (2014) 'Flying into aerospace's next generation', Industrial Engineer, Vol. 46, No. 10, pp.38-43.

Antoni, J., Griffaton, J., André, H., Avendaño-Valencia, L.D., Bonnardot, F., Cardona-Morales, O., ... and Acuña, D.Q. (2017) 'Feedback on the Surveillance 8 challenge: vibration-based diagnosis of a Safran aircraft engine', Mechanical Systems and Signal Processing, Vol. 97, No. 12, pp.112-144.

Araci, Z., Al-Ashaab, A., Tariq, M.U., Braasch, J. and Simsekler, M.C.E. (2020) 'Creating knowledge environment during lean product development process of a jet engine', International Journal of Advanced Computer Science and Applications (IJACSA), Vol. 11, No. 5, pp.58-62.

Araci, Z.C., Al-Ashaab, A. and Maksimovic, M. (2016) 'Knowledge creation and visualisation by using trade-off curves to enable set-based concurrent engineering', The Electronic Journal of Knowledge Management, Vol. 14, No. 1, pp.75-88.

Araci, Z.C., Al-Ashaab, A., Lasisz, P.W., Flisiak, J.W., Maulana, M.I.I.M., Beg, N. and Rehman, A. (2017) 'Trade-off curves applications to support set-based design of a surface jet pump', Procedia CIRP, Vol. 60, No. 27, pp.356-361.

Balli, O. (2017) 'Exergy modeling for evaluating sustainability level of a high bypass turbofan engine used on commercial aircrafts', Applied Thermal Engineering, Vol. 123, No. 8, pp.138-155.

Berton, J.J., Jones, S.M., Seidel, J.A. and Huff, D.L. (2018) 'Noise predictions for a supersonic business jet using advanced takeoff procedures', The Aeronautical Journal, Vol. 122, No. 1250 , pp.556-571.

Biazzo, S., Panizzolo, R. and de Crescenzo, A.M. (2016) 'Lean management and product innovation: a critical review', Understanding the Lean Enterprise, pp.237-260, Springer, Cham.

Bitran, G.R. and Morabito, R. (1999) 'An overview of tradeoff curves in manufacturing systems design', Production and Operations Management, Vol. 8, No. 1, pp.56-75.

Chandiramani, K.L.. (1974) 'Diffraction of evanescent waves; applications to aerodynamically scattered sound and radiation from unbaffled plates', Journal of the Acoustical Society of America, Vol. 55, No. 19, pp.19-29.

Cooper, R.G. (2016) 'Agile-stage-gate hybrids: the next stage for product development blending agile and stage-gate methods can provide flexibility, speed, and improved communication in new-product development', Research-Technology Management, Vol. 59, No. 1, pp.21-29.

Correia, A.T., Stokic, D. and Faltus, S. (2014) 'Mechanisms for communication and knowledge sharing for set-based concurrent engineering', International Journal of Product Development, Vol. 19, No. 5, pp.328-347.

Gagliardi, P., Teti, L. and Licitra, G. (2018) 'A statistical evaluation on flight operational characteristics affecting aircraft noise during takeoff', Applied Acoustics, Vol. 134, No. 5, pp.8-15.

Gjestland, T. and Granøien, I.L. (2016) 'Noise surveys at five Norwegian airports', INTER-NOISE and NOISE-CON Congress and Conference Proceedings, August, Vol. 253, No. 8, pp.201-207, Institute of Noise Control Engineering.

Haselbach, F. and Parker, R. (2012) 'Hot end technology for advanced, low emission large civil aircraft engines', in Grant, I. (Ed.): 28th International Congress of the Aeronautical Sciences, p.3. 
Hebly, S.J. and Visser, H.G. (2015) 'Advanced noise abatement departure procedures: custom-optimised departure profiles', The Aeronautical Journal, Vol. 119, No. 1215, pp.647-661.

Iglesias-Merchan, C., Diaz-Balteiro, L. and Soliño, M. (2015) 'Transportation planning and quiet natural areas preservation: Aircraft overflights noise assessment in a national park', Transportation Research Part D: Transport and Environment, Vol. 41, No. 12, pp.1-12.

Kammerl, D., Schockenhoff, D., Hollauer, C., Weidmann, D. and Lindemann, U. (2017) 'A framework for sustainable product development', Sustainability through Innovation in Product Life Cycle Design, pp.21-32, Springer, Singapore.

Kennedy, B.M., Sobek, D.K. and Kennedy, M.N. (2014) 'Reducing rework by applying set-based practices early in the systems engineering process', Systems Engineering, Vol. 17, No. 3, pp.278-296.

Kerga, E., Taisch, M., Terzi, S., Bessega, W. and Rosso, A. (2014) 'Set-based concurrent engineering innovation roadmap (SBCE IR): a case on Adiabatic Humidification', International Journal of Design Creativity and Innovation, Vol. 2, No. 4, pp.1-32.

Khan, M.S., Al-Ashaab, A., Shehab, E., Haque, B., Ewers, P., Sorli, M. and Sopelana, A. (2013) 'Towards lean product and process development', International Journal of Computer Integrated Manufacturing, Vol. 26, No. 12, pp.1105-1116.

Kopsch, F. (2016) 'The cost of aircraft noise - does it differ from road noise? A meta-analysis', Journal of Air Transport Management, Vol. 57, No. 10, pp.138-142.

Kyprianidis, K.G. and Dahlquist, E. (2017) 'On the trade-off between aviation NOx and energy efficiency’, Applied Energy, Vol. 185, No. 1, pp.1506-1516.

Lawton, R.N. and Fujiwara, D. (2016) 'Living with aircraft noise: airport proximity, aviation noise and subjective wellbeing in England', Transportation Research Part D: Transport and Environment, Vol. 42, No. 1, pp.104-118.

Lefèvre, M., Carlier, M.C., Champelovier, P., Lambert, J., Laumon, B. and Evrard, A.S. (2017) 'Effects of aircraft noise exposure on saliva cortisol near airports in France', Occupational and Environmental Medicine, Vol. 74, No. 8, pp.612-618.

Lindlöf, L., Söderberg, B. and Persson, M. (2013) 'Practices supporting knowledge transfer an analysis of lean product development', International Journal of Computer Integrated Manufacturing, Vol. 26, No. 12, pp.1128-1135, doi: 10.1080/0951192X.2011.651160.

Maksimovic, M., Al-Ashaab, A., Shehab, E., Flores, M., Ewers, P., Haque, B., Furian, R., von Lacroix, F. and Sulowski, R. (2014) 'Industrial challenges in managing product development knowledge', Knowledge-Based Systems, Vol. 71, pp.101-113, Elsevier, doi: 10.1016/j.knosys.2014.07.016.

Morgan, J.M. and Liker, J.K. (2006) The Toyota Product Development System: Integrating People, Process, and Technology, Productivity Press, New York.

Naqavi, I., Wang, Z-N. and Tucker, P., Mahak, M. and Strange, P. (2016) 'Far-field noise prediction for jets using large-eddy simulation and Ffowcs Williams-Hawkings method', International Journal of Aeroacoustics, Vol. 15, doi: 10.1177/1475472X16672547.

NASA (2020) General Thrust Equation [online] https://www.grc.nasa.gov/www/k-12/ VirtualAero/BottleRocket/airplane/thrsteq.html (accessed January 2020).

Nogueira, P., R. Sirotto, J., Miotto, R.F., Cavalieri, A.V., Cordioli, J. and Wolf, W. (2018) 'Acoustic radiation of subsonic jets at the vicinity of an inclined flat plate', The Journal of the Acoustical Society of America, Vol. 146, No. 50, doi: 10.2514/6.2018-2976.

Nonaka, I., Kodama, M., Hirose, A. and Kohlbacher, F. (2014) 'Dynamic fractal organizations for promoting knowledge-based transformation - a new paradigm for organizational theory', European Management Journal, Vol. 32, No. 1, pp.137-146, doi: 10.1016/j.emj.2013.02.003.

Nonaka, I., Toyama, R. and Konno, N. (2000) 'SECI, Ba and leadership: a unified model of dynamic knowledge creation', Long Range Planning, Vol. 33, No. 1, pp.5-34, doi: 10.1016/S0024-6301(99)00115-6. 
Otto, K.N. and Antonsson, E.K. (1991) 'Trade-off strategies in engineering design', Research in Engineering Design, Vol. 3, No. 2, pp.87-103, Springer.

Papamoschou, Dimitri. (2018) 'Wavepacket modeling of the jet noise source', International Journal of Aeroacoustics, Vol. 17, pp.52-69, doi: 10.1177/1475472X17743653.

Pershing, B. (1968) 'Dragster aerodynamics, streamlining versus weight', Aerodynamics of Sports and Competition Automobiles, Proc of the AIAA Symp, Los Angeles, CA, USA, pp.39-51.

Rauch, E., Dallasega, P. and Matt, D.T. (2016) 'The way from lean product development (LPD) to smart product development (SPD)', Procedia CIRP, Vol. 50, No. 26, pp.26-31.

Raudberget, D. (2010) 'Practical applications of set-based concurrent engineering in industry', Strojniski Vestnik/Journal of Mechanical Engineering, Vol. 56, No. 11, pp.685-695.

Saadon, S. and Talib, A.A. (2016) 'An analytical study on the performance of the organic Rankine cycle for turbofan engine exhaust heat recovery', IOP Conference Series: Materials Science and Engineering, October, Vol. 152, No. 1, p. 012011, IOP Publishing.

Sandberg, M., Tyapin, I., Kokkolaras, M., Lundbladh, A. and Isaksson, O. (2017) 'A knowledge-based master model approach exemplified with jet engine structural design', Computers in Industry, Vol. 85, No. 2, pp.31-38.

Schuh, G., Gartzen, T., Soucy-Bouchard, S. and Basse, F. (2017) 'Enabling agility in product development through an adaptive engineering change management', Procedia CIRP, Vol. 63, No. 50, pp.342-347.

Sobek, D.K., Ward, A.C. and Liker, J.K. (1999) 'Toyota's principles of set-based concurrent engineering', Sloan Management Review, Vol. 40, No. 2, pp.67-84.

Tariq, M.U. (2013) 'Using knowledge management for organizational learning', International Journal for Management and Science Technology, Vol. 1, No. 1, pp.1-11.

Tariq, M.U. (2015) 'Hypothetico-deductive method: a comparative analysis', Journal of Basic and Applied Research International, April, Vol. 7, No. 4, pp.228-231.

Tariq, M.U. (2013) 'A Six Sigma based risk management framework for handling undesired effects associated with delays in project completion', Journal of Lean Six Sigma, Vol. 4, No. 3, pp.265-279

Tariq, M.U., Bashir, B.B., Babar, M. and Sohail, A. (2020) 'Code readability management of high-level programming languages: a comparative study', International Journal of Advanced Computer Science and Applications (IJACSA), Vol. 11, No. 3, pp.595-602.

Tortorella, G.L., Marodin, G.A., Fettermann, D.D.C. and Fogliatto, F.S. (2016) 'Relationships between lean product development enablers and problems', International Journal of Production Research, Vol. 54, No. 10, pp.2837-2855.

Trojanek, R., Tanas, J., Raslanas, S. and Banaitis, A. (2017) 'The impact of aircraft noise on housing prices in Poznan', Sustainability, Vol. 9, No. 11, p.2088.

Tyagi, S., Choudhary, A., Cai, X. and Yang, K. (2015) 'Value stream mapping to reduce the lead-time of a product development process', International Journal of Production Economics, Vol. 160, No. 2, pp.202-212.

Wang, Z. and Wang, N. (2012) 'Knowledge sharing, innovation and firm performance', Expert Systems with Applications, Vol. 39, No. 10, pp.8899-8908, doi: 10.1016/j.eswa.2012.02.017.

Ward, A.C. and Sobek, D.K. (2014) Lean Product and Process Development, 2nd ed., Lean Enterprise Institute, Cambridge, MA, USA.

Womack, J. (2006) 'A lesson to be learned', Manufacturing Engineer, Vol. 85, No. 2, pp.4-5.

Zaman, K., Bridges, J. and Huff, D.L. (2012) 'Evolution from 'tabs' to 'Chevron technology' a review', Noise Notes, Vol. 11, pp.27-48, doi: 10.1260/1475-4738.11.1.27. 